\title{
The Effect of Rooftop Garden on Reducing the Internal Temperature of the Rooms in Buildings
}

\author{
Lamees Alhashimi, Lujain Aljawi, Raneem Gashgari, Abrar Alamoudi \\ Department of Industrial Engineering, King Abdulaziz University \\ Jeddah 21589, Saudi Arabia \\ lalhashimi0001@stu.kau.edu.sa; laljawi0001@ stu.kau.edu.sa; \\ rgashgari0001@stu.kau.edu.sa; aalamoudi0001@stu.kau.edu.sa
}

\begin{abstract}
With the rapid industrialization and urban expansion pushing cities to build skyscrapers, streets, and homes often at the expense of plant life and vegetation people have forgotten the real reasons for vegetation. For most them, trees and other vegetation serve merely as a luxury or to make cities look prettier. While providing aesthetic value is a well-known fact, the integration of plants and other wildlife can also benefit cities in other ways. It is not until recently that people realized the effect of uprooting plants, one of these effects is the Urban Heat Island Effect. To alleviate its effects, urban planners, in developed countries, have been using rooftop gardens as a way to merge vegetation in urban areas. The purpose of this research is to study the effectiveness of rooftop gardens in reducing the Urban Heat Island Effect in the climate and conditions in Jeddah, Saudi Arabia. This research uses a one sample t-test to measure the extent of the effects. Model buildings; similar to materials that make up real buildings in Jeddah; with and without a rooftop garden were used in the experiment. The internal temperature of each building was recorded at regular intervals for a period of time, and the results were then compared. The results showed that there is a difference in temperatures between the two buildings especially, in the peak temperatures. It is expected that if rooftop gardens were implemented on a large scale, will reduce energy consumption and eventually energy bill. Consequently, the rooftop garden will be a financially and an environmentally beneficial idea.
\end{abstract}

Keywords: Rooftop Garden, Urban Heat Island, Internal Temperature, Designed Experiment, Energy Saving.

\section{Introduction}

\subsection{Background Research}

Ever since pre-modern times, people have integrated plants and vegetation in their cities, or at least learned to co-exist with nature. Old cities such as Tehran in Iran display this fact [1]. In those times, there were some human-caused extinction of wild life; however, the impact was relatively small on the whole. In the modern era, the growth of cities and human activities has prompted a separation between nature and humans. Due to the rapid expansion of human civilization, forests, grasslands, and fields are being replaced with asphalt, concrete, and steel.

For most people, trees and other vegetation serve merely as a luxury or to make cities look prettier. While providing aesthetic value is a well-known fact, the integration of plants and other wildlife can also benefit cities in other ways. By providing shade for buildings and pavements, plants can cool buildings; therefore, reducing energy use, and also slowing the degradation of pavements which reduces the costs for maintaining them [2]. Plants and vegetation can also improve air quality and reduce greenhouse gas emissions either directly by absorbing greenhouse gasses such as carbon dioxide from the atmosphere, or indirectly as a result of the reduced energy use. In addition to reducing energy use and greenhouse gas emissions, plants and vegetation provide a home for a great number of species. Psychologists have even linked plants and greenery with mental revitalization, and an increase in cognitive and developmental skills in children [3][4].

Even though the benefits of the inclusion of vegetation in urban areas are well-known, many cities were planned without taking into account trees and other plant life. In fact, in many cases, vegetation had to be removed to make way for skyscrapers, housing developments, and malls. According to the Food and Agriculture Organization of the United Nations, around 13 million hectares of forest were converted to other uses or lost through natural causes each year in the last decade compared to 16 million hectares per year in the 1990s [5]. The result is a phenomenon known as the Urban Heat Island Effect. 
Nowadays, the most prominent phenomenon associated with high temperatures in most cities is the "Urban Heat Islands (UHIs)". It directly affects buildings as a result of the high temperature of the surrounding air which is always about warmer 10 degrees in cities than in surrounding rural areas. This difference is due to four factors. First, urbanization changes the thermal properties of the earth surface. For example, areas of concrete, asphalt and other building materials replace vegetation. The result of these changes is a higher surface temperature of the urbanized area. Second, buildings and other urban structures in the urban area are obstacles to the wind. The obstacles alter the general flow patterns and generate air turbulence. Third, urbanization changes the moisture conditions at the earth surface. The relatively moist vegetated surface of the original rural area is replaced by a dry surface. Very little evaporation occurs from the surface which results in a drier and warmer surface air over the city. Last, the urbanized area emits heat and pollutants to the atmosphere.

Recently, people are becoming more aware of the Urban Heat Island Effect and are looking into new ways to reduce its effects. Researchers have been developing techniques and building materials that absorb less heat such treating asphalt with emulsion sealcoats to make it reflect more light. However, it is impractical to tear down all the existing buildings and streets in order to rebuild them using the new techniques and materials. So, how can we work with current buildings to reduce the Urban Heat Island Effect? One great alternative is to install gardens on the rooftops of buildings.

This research will focus on how to use rooftop gardens to reduce this phenomenon in Jeddah, which located on the coastal plain bordering the Red Sea. As most of Saudi Arabia is a desert, Jeddah features an arid climate. However, the local climate of Jeddah has changed as a result of the human and industrial activities which have negative effects on many aspects such as the government's income and human health because of the following reasons:

1.The (UHIs) will increase the energy consumption that required for cooling and air conditioning of the internal buildings to secure the required level of comfortable temperature.

2.The country is in need to generate more electric power by burning more fuel that will increase the proportion of pollutants emitted into the air.

3. While the presence of ozone in the upper atmosphere protects the earth from ultraviolet radiation that harmful to human health, the UHIs leads to an increase in the size of the hole in the ozone layer near the ground as a result of the high temperature.

\subsection{Similar Work}

The effect of urban heat island has been an old area of interest to study. It was first investigated by the British scientist Luck Howard in the 1810s [6]. Many researchers have since outlined the problem, one study by [7] which was done in New York City showed that the effect of UHI is greater over the city than over the surrounding rural areas. Another old study by [8] addressed the relationship between the size of the city and the magnitude of the UHI. From that point, many means of reducing UHIs were studied. [9] exanimated different white coatings and building materials. The result indicated a 20-40\% direct energy saving by raising the albedo of a building. While [10] verified that vegetation of the city of New Jersey could mitigate air pollution, energy consumption and it's economically efficient.

Many studies address the vegetation in cities. For example, [11] claims planting urban trees can potentially reduce carbon emission and the energy consumptions of buildings. The trees reduce the solar heat that is absorbed through the window and other types heat gains from surroundings. The calculations showed that planting one tree in Los Angeles would save $18 \mathrm{~kg}$ of carbon per year. Other paper [12] evaluated UHI of four different areas in New York City; their result exhibited a difference of 2 degree Celsius between Columbia University (least vegetated area) and Fieldston (most vegetated area).

The effect of vegetation on warm countries like Brazil was studied. A study by [13] address the issue of the rise of temperature in the upcoming decades. Using ENVI_MET V4 to simulate the impact of vegetation on microclimates, they tested four scenarios with various trees distribution. The results showed the scenarios with trees compared to the base case (no trees) did have a cooling effect on the air temperature but it is still limited. However, the effect on mean radiant temperature is clear.

Other studies focused on studying the rooftop garden benefits in specific. In the University of Waterloo [14], a hypothesis was assumed that rooftop gardens benefit in many areas including the societies economic, education environmental, and social sector. An idea was proposed to plant a rooftop garden in one of Waterloo University's buildings (Environmental Studies 1 building) to see if a rooftop garden can reduce the urban heat island effect and improve air quality. The results were supported by qualitative methods, as the implementation processes of the experiment were unable to be done. It was shown that rooftop garden systems are both beneficial and feasible on the campus. Another university, The National 
University of Singapore [15], experimented to show the effect of the rooftop garden on consuming the energy of commercial building in Singapore. To help determine the energy consumption and cooling load of five-story hypothetical commercial building, DOE-2 energy simulation program was used. Three roofs were stimulated (exposed roof, typical flat roof, roof with a rooftop garden). The plants and soil thickness were considered. The result showed that installing rooftop garden can save 0.6 to $14.5 \%$ in the annual energy consumption and as the soil thickness increases it will result in reducing the building energy consumption. The Climate Protection Partnership Division in the U.S de-scribe in their work [16] the causes and impressions of summertime urban heat is-lands and endorses strategies for lowering temperatures in the U.S by planting green roofs. The beneficial of green roofs and how it lowers the temperature of buildings were discussed. A study indicated by [17] the benefits of green roof and the impact of it on a residential building in the desert environment were showed. The result helped determine which roof types reduce energy consumption during the day and night. With the help of Onset $\mathrm{HOBO}{ }^{\circledR}$ data loggers, the temperature was recorded by re-searchers. Three simulating roof types were done (insulated cool, insulated green, and un-insulated green) in eight different pods. A weather station was installed to measure precipitation, wind speed, and temperature in order to monitor the effects of evapotranspiration and therefore plant survival. It was found that on average, the un-insulated green roof had the coolest daytime temperatures and the warmest night-time temperatures, while the insulated cool roof was the opposite.

\section{Problem Description}

\subsection{Problem}

The desert climate of Saudi Arabia greatly affects residential and commercial buildings' electric bills such that people use air conditioners more frequently. At present, the Saudi government subsidizes the cost of electricity. However, as many cities grow, the actual cost of electricity bills is increasing too. Soon, the government will not be able to subsidize the cost, and the residents of Saudi Arabia will have to pay a great amount of money for electricity.

This paper aims to investigate the effectiveness of rooftop gardens in reducing the internal temperature of commercial and residential buildings in the city of Jeddah, Saudi Arabia. Thus, the hypothesis for this experiment that placing gardens on the rooftops of residential and commercial buildings will noticeably reduce the internal temperature of the rooms in the building.

\subsection{Variables}

Three kinds of variables are used in this experiment. The first one is the independent variable which is the planting status with two levels: with and without a rooftop garden. The second is the dependent variable, and it is the internal temperature in the buildings. The last one is the variables that are controlled during the experiment these variables are; the circumstances surrounding (location, external temperature), model buildings, thermometers, plants on top of the roof and time.

\section{Methodology and Results}

\subsection{Procedure}

A drawing sheet was constructed using Solid Works illustrating the needed measurements for the model building shown in Fig. 1. An experienced builder was consulted to help determine the appropriate materials that would be similar to materials that make up real buildings in Jeddah. The material used for the model buildings is concrete sheetrock (Drywall). The two model houses were built according to the specified measurements (see Fig. 2). A plant nursery was visited to buy plants that are indigenous to our climate and are commonly found in Jeddah. Two digital thermometers were used to measure the internal temperature where it was placed inside the model buildings. The two model buildings were placed outside directly under the sun and the internal temperature in each building was recorded every hour from 6 a.m. to 6 p.m. The recording of the temperature continued for three consecutive days. 

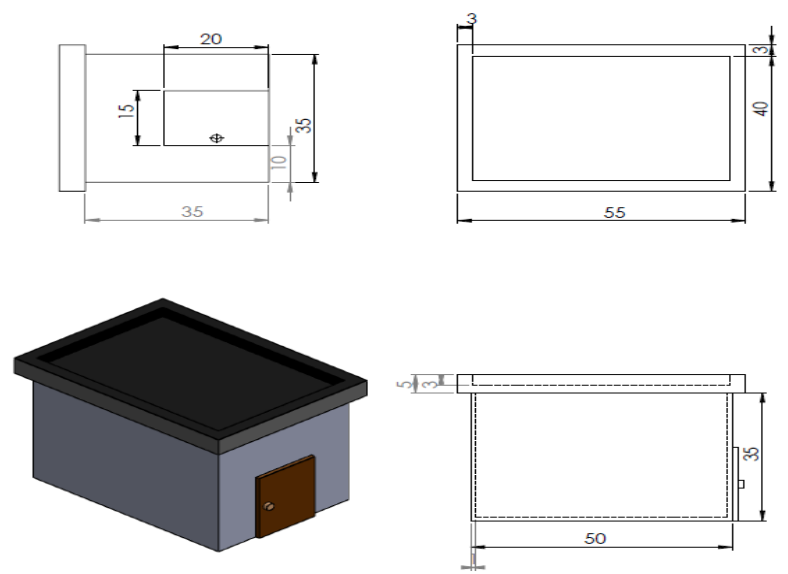

Fig. 1: Drawing sheet for the model building.

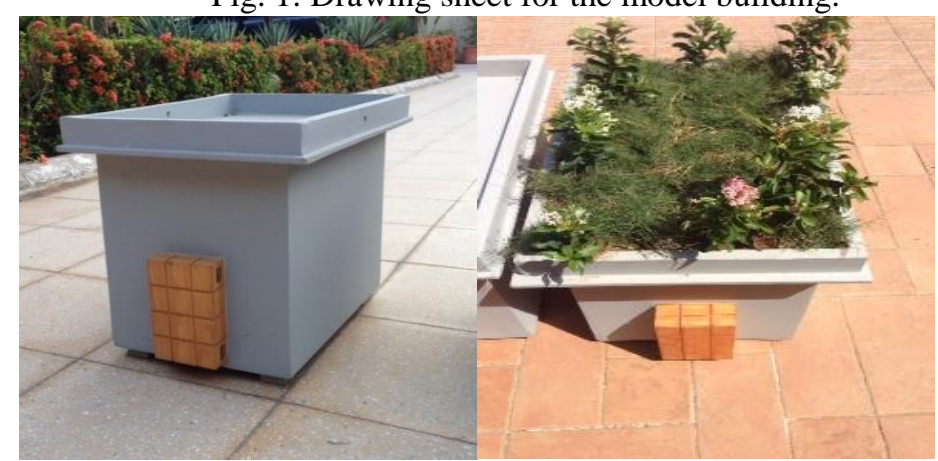

Fig. 2: The two model buildings used in the experiment (left without rooftop garden while right with rooftop garden).

\subsection{Data Analysis}

Readings were taken each day from 6:00 a.m. to 6:00 p.m. on the course of three days, which resulted in a total of 39 readings (see Table 1). Initially, each day's readings were tabulated, and graphed. All the information from the three days suggests that the difference in temperature between the model buildings with and without the rooftop garden is greatest when the temperature reaches its peak for the day, from about 10:00 to 3:00 p.m. and can be seen in Fig. 3 . After computing the mean temperatures for the three days, the difference in average temperatures reinforces the idea that the difference in temperature starts very small, and as the day progresses and the weather gets hotter, the difference increases, reaching a high at 5.2 degrees. One sample t-test was used to test the hypothesis that the temperature is lower in the building with a rooftop garden.

$$
H_{0}=\mu \mathrm{w} / \mathrm{o} \mathrm{RTG}-\mu \mathrm{w} \mathrm{RTG}=0 \text { vs } \quad H_{1}=\mu \mathrm{w} / \mathrm{o} \mathrm{RTG}-\mu \mathrm{w} \mathrm{RTG}>0
$$

The results indicated that the difference in mean temperature is significantly different from zero. To reject the null hypothesis, the p-value should be less than 0.05. Based on the measurements, the p-value was 0.0095 (see Table 2) which strongly suggests that the difference was not due to chance but was most likely due to the effect of the rooftop garden in reducing the internal temperature of the buildings.

\subsection{Results}

Results of the previous experiments demonstrate that there is indeed a difference in the internal temperatures of the model buildings. The values from the experiment are presented in Table 1. This proves the hypothesis which states: Placing gardens on the rooftops of residential and commercial buildings will noticeably reduce the internal temperature in a building. It was noticed that during the peak hours, the difference in the internal temperature increases. This shows 
that there is an inverse relation between the external temperature and the internal temperature of a building with a rooftop garden.

In essence, rooftop gardens provide numerous benefits including economical, ecological, and financial benefits, such such as: reducing the internal temperature of buildings, whether small or large buildings such as commercial buildings; therefore, reducing electricity bills of cooling in Saudi Arabia. Rooftop gardens can also save on energy since rooftop plants supply buildings with additional insulation and shade. Rooftop gardens can absorb rainfall, reducing run-off in rainy weather. It creates space for agriculture as well as it adds beauty to the landscape and increases air quality. Moreover, it diminishes the urban heat island effect by reducing heat radiation.

Table 1: The reading of each day and the average temperature of the three days.

\begin{tabular}{|c|c|c|c|c|c|c|c|c|c|c|}
\hline & & \multicolumn{2}{|c|}{ Day 1} & \multicolumn{2}{|c|}{ Day 2} & \multicolumn{2}{|c|}{ Day 3} & \multicolumn{3}{|c|}{ Average } \\
\hline $\begin{array}{c}\text { Reading } \\
\#\end{array}$ & Time & $\begin{array}{c}\text { Without } \\
\text { RTG }\end{array}$ & $\begin{array}{l}\text { With } \\
\text { RTG }\end{array}$ & $\begin{array}{l}\text { Without } \\
\text { RTG }\end{array}$ & $\begin{array}{l}\text { With } \\
\text { RTG }\end{array}$ & $\begin{array}{c}\text { Without } \\
\text { RTG }\end{array}$ & $\begin{array}{l}\text { With } \\
\text { RTG }\end{array}$ & $\begin{array}{c}\text { Without } \\
\text { RTG }\end{array}$ & $\begin{array}{l}\text { With } \\
\text { RTG }\end{array}$ & $\begin{array}{c}\text { Difference in } \\
\text { Temp. }\end{array}$ \\
\hline 1 & $6: 00$ & 26.4 & 26.5 & 26.4 & 25.5 & 26.7 & 26.3 & 26.5 & 26.1 & 0.4 \\
\hline 2 & 7:00 & 26.1 & 26.7 & 26.4 & 26.6 & 26.1 & 26.9 & 26.2 & 26.7 & -0.5 \\
\hline 3 & $8: 00$ & 28.1 & 27.9 & 26.1 & 26.9 & 27.3 & 28.1 & 27.2 & 27.6 & -0.5 \\
\hline 4 & 9:00 & 28.6 & 29.0 & 27.3 & 28.1 & 28.6 & 28.0 & 28.2 & 28.4 & -0.2 \\
\hline 5 & $10: 00$ & 36.3 & 32.3 & 34.5 & 30.7 & 36.5 & 32.4 & 35.8 & 31.8 & 4.0 \\
\hline 6 & $11: 00$ & 42.6 & 35.6 & 40.2 & 35.9 & 40.0 & 35.7 & 40.9 & 35.7 & 5.2 \\
\hline 7 & $12: 00$ & 45.1 & 39.7 & 42.4 & 37.5 & 41.3 & 37.0 & 42.9 & 38.1 & 4.9 \\
\hline 8 & $13: 00$ & 42.2 & 39.5 & 42.4 & 39.5 & 42.0 & 37.3 & 42.2 & 38.8 & 3.4 \\
\hline 9 & $14: 00$ & 42.4 & 42.0 & 42.5 & 39.5 & 42.4 & 39.5 & 42.4 & 40.3 & 2.1 \\
\hline 10 & $15: 00$ & 42.5 & 42.0 & 42.5 & 42.0 & 42.4 & 39.3 & 42.5 & 41.1 & 1.4 \\
\hline 11 & $16: 00$ & 42.6 & 42.0 & 40.0 & 39.5 & 42.6 & 39.9 & 41.7 & 40.5 & 1.3 \\
\hline 12 & $17: 00$ & 34.8 & 33.9 & 30.0 & 30.9 & 34.9 & 35.7 & 33.2 & 33.5 & -0.3 \\
\hline 13 & $18: 00$ & 31.6 & 32.6 & 30.2 & 30.6 & 31.5 & 31.3 & 31.1 & 31.5 & -0.4 \\
\hline
\end{tabular}

Table 2: A hypothesis test: the mean vs. hypothesized value.

Hypothesized Value

Mean Difference in Temp.

Std. Dev.

Std. Error

n

df

$\mathbf{t}$

P-value (one-tailed, upper)
0.0000

1.5949

2.1212

0.5883

13

12

2.71

.0095 


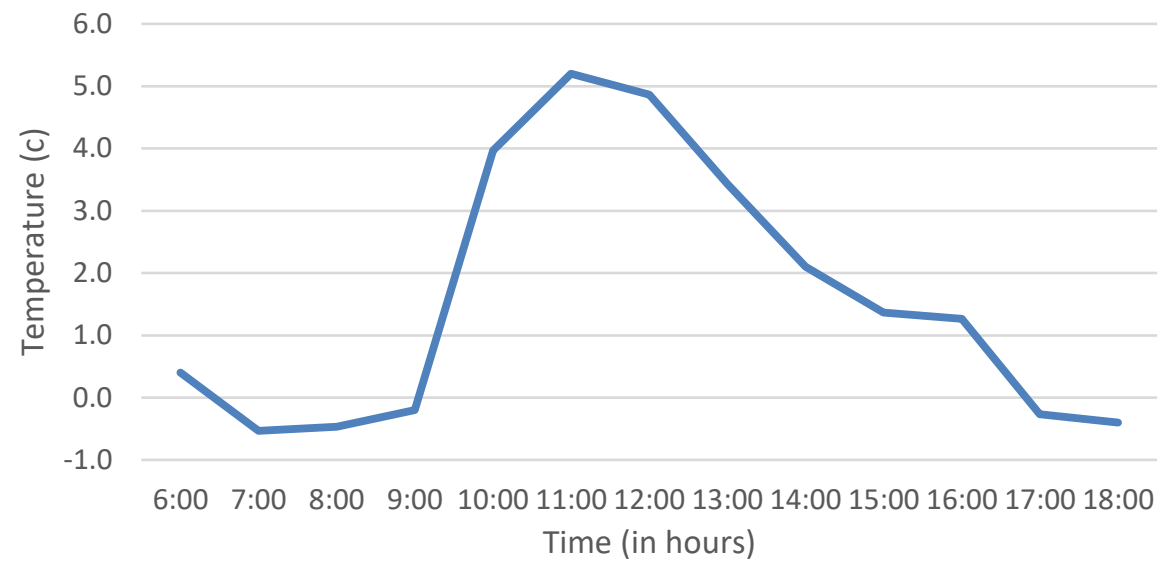

Fig. 3: A line graph representing the average data of the three days.

\section{Conclusion}

In the end, the experiment of building a model house that provided a rooftop garden proved the hypothesis of this research which says that the rooftop garden building experienced much lower first internal temperatures in comparison to the traditional roof as it provided direct shading and effectively reduced the absorption of solar radiation or reduced insulation. Also, it released heat less quickly because the rooftop garden would reduce heat flow through the roof and insulate the building, so it will reduce the need for either cooling or heating especially in Saudi region as it could provide a convenient food source in urban areas.

It must be noted that the designed experiment does have some acknowledged limitations. The first limitation is due to the model building itself. The small size of the model building does prove that there is a relationship between rooftop gardens and the internal temperature of a building. It might not, however, reflect the actual extent of the results. Also, the materials of the model building were close to the materials that are used in real buildings; however, it was not identical. Another limitation is that the experiment was conducted in fall when the temperature isn't that high. It is expected that better results would've been yielded in the summer time. In conclusion, rooftop gardens are a financially and an environmentally beneficial idea.

Future work can be applied in progress of this research; for example, studying the effect of different desert plants that have a different characteristic from the plants that have been used. Another choice, studying the impact of other building materials which have different physical qualities and integrate it with this research findings. Furthermore, determine if different types of soil used in building the rooftop garden play a role in increasing or decreasing the efficiency of this research. Lastly, conducting a cost analysis to determine if rooftop gardens are feasible in the long run.

\section{Acknowledgements}

We would like to extend our sincere thanks to Dr. Abeer Alkholi for giving us a good guideline throughout numerous consultations. We would also like to thank all teaching staffs of the Engineering Faculty at King Abdulaziz University for their constant encouragement, support and guidance.

\section{References}

[1] K. Samiei, "Architecture and Urban Ecosystems: From Segregation to Integration - The Nature of Cities," The Nature of Cities, 2013. [Online]. Available: https://www.thenatureofcities.com/2013/05/26/architecture-and-urbanecosystems-from-segregation-to-integration/. [Accessed: 2016].

[2] J. Coma, G. Pérez, A. de Gracia, S. Burés, M. Urrestarazu and L. Cabeza, "Vertical greenery systems for energy savings in buildings: A comparative study between green walls and green facades," Building and Environment, vol. 111, pp. 228-237, 2017. 
[3] Asociación RUVID, "Project to integrates vegetation in building facades," ScienceDaily, 2012. [Online]. Available: https://www.sciencedaily.com/releases/2012/10/121030101429.htm. [7 Mar, 2016].

[4] A. Taylor, F. Kuo and W. Sullivan, "Coping with add: The Surprising Connection to Green Play Settings," Environment and Behavior, vol. 33, no. 1, pp. 54-77, 2001.

[5] FAO, "Global Forest Resources Assessments," Food and Agriculture Organization of the United Nations, 2015. [Online]. Available: http://www.fao.org/forest-resources-assessment/en/. [2016].

[6] H. Akbari, "Shade trees reduce building energy use and $\mathrm{CO} 2$ emissions from power plants," Environmental Pollution, vol. 116, pp. S119-S126, 2002.

[7] T. Susca, S. Gaffin and G. Dell'Osso, "Positive effects of vegetation: Urban heat island and green roofs," Environmental Pollution, vol. 159, no. 8-9, pp. 2119-2126, 2011.

[8] N. Wong, D. Cheong, H. Yan, J. Soh, C. Ong and A. Sia, "The effects of rooftop garden on energy consumption of a commercial building in Singapore," Energy and Buildings, vol. 35, no. 4, pp. 353-364, 2003.

[9] A. Dam, C. Walke and C. Wilson, "The Future of Rooftop Gardens on the University of Waterloo Campus," ERS, 2000.

[10] D. Duarte, P. Shinzato, C. Gusson and C. Alves, "The impact of vegetation on urban microclimate to counterbalance built density in a subtropical changing climate," Urban Climate, vol. 14, pp. 224-239, 2015.

[11] US EPA, "Heat Island Compendium | US EPA," US EPA, 2012. [Online]. Available: https://www.epa.gov/heatislands/heat-island-compendium.

[12] L. Milburn, A. Fernández-González, T. Jones, F. Solano and E. Martínez-Wong, "Wasted space: altering building temperatures by greening barren rooftops in the desert Southwest," in Landscape Legacy: Landscape Architecture and Planning Between Art and Science, Netherlands, 2011.

[13] M. Roth and W. Chow, "A historical review and assessment of urban heat island research in Singapore," Singapore Journal of Tropical Geography, vol. 33, no. 3, pp. 381-397, 2012.

[14] T. Oke, "City size and the urban heat island," Atmospheric Environment (1967), vol. 7, no. 8, pp. 769-779, 1973.

[15] R. Bornstein, "Observations of the Urban Heat Island Effect in New York City," Journal of Applied Meteorology, vol. 7, no. 4, pp. 575-582, 1968.

[16] A. Rosenfeld, H. Akbari, S. Bretz, B. Fishman, D. Kurn, D. Sailor and H. Taha, "Mitigation of urban heat islands: materials, utility programs, updates," Energy and Buildings, vol. 22, no. 3, pp. 255-265, 1995.

[17] W. Solecki, C. Rosenzweig, L. Parshall, G. Pope, M. Clark, J. Cox and M. Wiencke, "Mitigation of the heat island effect in urban New Jersey," Environmental Hazards, vol. 6, no. 1, pp. 39-49, 2005. 